\title{
Producing Electricity by Concentrated Solar Energy
}

\author{
Hassan Abdulmouti \\ Associate Professor, Department of Mechanical Engineering Division, Sharjah Men's College, Higher Colleges of \\ Technology, P. O. Box 7946, Sharjah, UAE, Phone: +971 22066557 e-mail: habdulmouti@ hct.ac.ae, alternative e-mail: \\ hassanabujihad@hotmail.com
}

\begin{abstract}
Energy sources are crucial for the development and growth of economies and civilizations. Solar energy is alternative energy to generate electrical power. The motivation of this paper is to examine the applicability of a solar sphere experimentally which is a new concentrated photovoltaic technology. The function of this new technology is to collect solar energy and concentrate it into a small region as a focal point. The focused solar energy can generate a massive amount of power which is used to produce more electricity than normal photovoltaic panels. The experiments are carried out for several kinds of shapes and models that have the same volume, different volumes, and different fluid mediums. The tested shapes are a full sphere, the upper semi-sphere, the bottom semi-sphere, cylinder in a horizontal and a vertical position, vertical half-cylinder, horizontal half cylinder with the upper flat surface, a horizontal half cylinder with the lower flat surface, and cube. Then, these shapes are compared with normal photovoltaics (PV) that have the same section area as these shapes. With respect to the volume and size, many different volumes are tested. The equivalent diameters are $10 \mathrm{~cm}$ diameter, $12 \mathrm{~cm}$ diameter, $14 \mathrm{~cm}$ diameter, and $30 \mathrm{~cm}$ diameter. Regarding the materials, various mediums and materials (solids, liquids, gasses) are used. The solid materials are glass, crystal, and acrylic while the liquids are oil, water, and alcohol, and the used gas is the air. Moreover, the thickness of the shape is also tested, by using $4 \mathrm{~mm}, 5 \mathrm{~mm}, 6 \mathrm{~mm}$, and $8 \mathrm{~mm}$ acrylic thicknesses. After a comparison between different designs, the results of the experiments reveal that the full sphere with the same material produces a higher power output than other shapes, it produces around triple the power output of the semi-spheres and 4 times the power output of a PV with the same area. The best shapes that produce the highest output power are arranged from the highest output power to the lower as follows: full sphere, semi-sphere with dawn flat surface, semi-sphere with an up flat surface, horizontal half cylinder with the upper flat surface, horizontal half cylinder with the lower flat surface, vertical half-cylinder, vertical cylinder, horizontal cylinder, and cube. The results clarify that increasing the size of the sphere results in an increase in the power output. Where the $12 \mathrm{~cm}$ diameter sphere produces 0.8 times the power output of the 10 $\mathrm{cm}$ diameter sphere, and the $14 \mathrm{~cm}$ diameter sphere produces 0.9 times the power output of the $12 \mathrm{~cm}$ diameter sphere, while the $30 \mathrm{~cm}$ diameter sphere produces around 4 times the power output of the $12 \mathrm{~cm}$ diameter one. In addition, it was verified that increasing the thickness of the ball yields in increasing the output power, it is confirmed that increasing the thickness by $1 \mathrm{~mm}$ yields in increasing the output power by 0.8 times. The experiments show that all solid materials produce the highest power output. However, these solid materials produce high heat at the same time, so they are not desirable for generating electricity. Moreover, it was noted that the sphere filled with oil produces 1.5 times more power output than the one filled with alcohol while the sphere filled with alcohol produces double the power output of the sphere filled with water. The sphere filled with air had the lowest power output compared to the other substances.
\end{abstract}

Keywords: Renewable; Energy; Innovation; Solar; photovoltaic cells; Solar power and sphere.

\section{Introduction}

The need for various energy sources with regards to future energy supply, environmental impact, and energy conservation is an important issue that many countries and organizations are looking for recently. Energy sources are crucial for the development and growth of economies and civilizations. The problems of energy and climate change have finally ended up where they belong at the heart of public attention. At the time numerous experts were already calling for a speedy restructuring of the entire energy supply. As countries become more developed there is a greater demand for energy because people get more materialistic and buy more products that use energy both in their manufacture as well as in their use. Also, as countries develop their industries a large consumer of energy is needed. Furthermore, as rural (village) communities develop they use more energy because they are able to afford labor-saving equipment, tools, and gadgets that are taken for granted in the developed world, like agricultural machinery, dairy farm equipment, TVs, computers, cars, etc. Energy is required not only in running these devices but also in their manufacture and usages Hassan et al. (2018) and Hassan et al. (2019). 
Our civilized society encounters various hazards related to food, water resources, and the environment especially with the emergence of a new technological frontier. These hazards are related to energy. Therefore, technology dealing with energy becomes more important. Research and development activities in power and energy have grown exponentially over the past several decades. Studies estimate that there will be a big energy peak by $2016-2040$. The rapid growth in energy consumption will create a growing energy demand. Oil production supply will grow at a slower rate compared to demand, causing an energy crisis after the peak point due to expanded shortage, which will disturb and downsize economies, and this will lead to a rapid decline in production due to collapsed industries. Providing the world's energy demands is one of the most urgent and difficult challenges that facing our society. The critical challenges nowadays are to supply electricity world from alternative resources and avoid using fossil fuels Hassan et al. (2018), Hassan et al. (2019), and Hassan (2013).

On the other hand, Energy and the environment have a strong relationship. The production and consumption of energy are some of the biggest causes of environmental damage on earth. It leads to large amounts of the destruction of natural landscapes and habitants through the process of fuel extraction, pollution of soil, climate change. Energy is at the heart of many of the world's current environmental problems and possess many problems for sustainable development. As countries get richer, they use more energy because everybody gets cars and electrical goods M. Devarj and S. Shanmuga (2016) and Robants. S (2014).

And yet renewable energy is the simple solution. Renewable energy could completely cover all our energy supply needs within a few decades. This is the only way to end our dependence on energy sources like oil and uranium, which are so costly both in financial terms and in the havoc, they wreak on our environment. Hence, renewable energy can satisfy our hunger for energy in a way that is sustainable and compatible with the climate. Large amounts of renewable and clean energy are required to sustain the energy needs of a growing world population. Renewable energy is the alternative source to generate electricity. Solar energy is the only natural energy resource that can keep up with human consumption. The sun is the main source of energy. Therefore, collecting the energy directly from the sun intuitive approach.

The solar sphere is a new idea that gives us a higher efficiency than the normal solar panel collector. It converts solar energy into electrical energy directly. It also has more advantages compared to the normal flat panel as follows: 1the solar panels should always face the sun. 2- these panels occupy a large place for ideal installation that may not be available even if they can face the right direction, nearby higher buildings may block the sunrays from some directions. 3 - the sun angles in the sky vary according to the days of the location and time of the year that the inclination of the panel can only be made optimal at certain times during the year. This leads to the use of the sun-tracking system, which is too expensive, impractical, and the difficulties in adjusting the inclinations manually Rhino (2016). The sphere technology can solve all the above issues.

A German architect, called Andre Broessel, was inspired by his daughter's toy marbles to design a solar sphere that can concentrate direct and diffuse light on a solar panel that tracks the movement of the sun. He was a finalist in the World Technology Network Award 2013. His design, named Rawlemon design, uses a high efficient Multijunction cell Fluke (2016). This solar system design, which was found to be a liquid-filled solar sphere, can directly convert sunlight into electricity. The solar sphere collects the solar radiation from all directions and then concentrates it on a small focal area of a highly efficient solar cell. A pyranometer is used to measure the solar irradiance and a multimeter is used to measure the electrical power out of the solar cell.

In this paper, the sphere technology is used and tested experimentally. The measurements are conducted for many designs, shapes, thicknesses, and sizes with different fluid mediums or materials during the whole year.

\section{Experimental Apparatus and design}

An experimental setup is designed as shown in Figure 1. The shape containers are made of acrylic. They are filled with fluid mediums or materials. The container (sphere in the figure) is set on a stand. The spherical ball receives and concentrates the sunlight into a focal point. The focal point is set and placed to be on the top of the Multi-junction concentrator cells device. This device is connected directly to a multimeter to read the output current and the voltage. The multi-junction concentrator solar cell which is consists of a concentrating system is used in the experiments, such as magnifying glass, to focus the solar radiation into a small area of the cell. This cell is attached to a heat sink. The multi-junction solar cell consists of three sub-cells or junctions, which convert different portions from the light into electricity. The first layer is GaInP and it is located in the top sub-cell. GaInAs is used for the middle sub-cell and Ge 
substrate is the third sub-cell. This type of cell can handle high temperatures and resist radiation exposure; therefore, it is used in the experiments because it is suitable for concentrated solar systems such as our system.

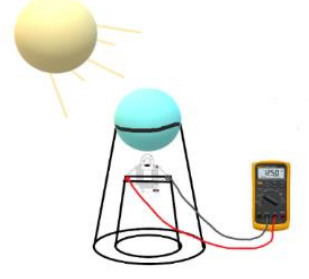

Fig. 1. Experimental Setup

The characteristics and specification of this multi-junction concentrator solar cell are listed as follows:

The dimensions of the whole-cell device are $9 \times 9 \mathrm{~cm} 2$

The dimensions of the cell without the focusing optics are $0.5 \times 0.5 \mathrm{~cm} 2$.

The theoretical maximum current is $1.55 \mathrm{~A}$.

The theoretical maximum voltage is $2 \mathrm{~V}$.

The theoretical maximum power output is around $3.2 \mathrm{~W}$.

A passive cooling system is, also provided to the cell, which is the heat sink. The heat sink is made of ceramic substrate with high thermal conductivity and electrical isolation Rhino (2016). The multimeter instrument is used to measure the electric values, such as voltage, current, and resistance of multi-junction solar cells [8]. Furthermore, the temperature of the cell is measured by using a thermocouple which is provided with the multimeter. The experiments are conducted for many kinds of shapes and models which have the same volume, different volumes and sizes, and different fluid materials and mediums in order to find out the best size, materials, and shape that produces higher electrical power. The experiments are conducted and repeated all over the year to cover all the circumstances of the year then the power output and the efficiency are calculated as an average of the year. The experiments are conducted about 20 days per month.

\subsection{Models, shape, and ordination}

In order to figure out the best shape for generating electrical power, different shapes and models are examined as follows:

- a full sphere

- the upper semi-sphere

- the bottom semi-sphere

- a cylinder in a horizontal position

- a cylinder in a vertical position

- vertical half cylinder

- horizontal half cylinder with the upper flat surface

- horizontal half cylinder with the lower flat surface

- cube

All the above shapes are examined for the three different volumes of $0.01047 \mathrm{~m}^{3}, 0.01508 \mathrm{~m}^{3}$, and $0.02053 \mathrm{~m}^{3}$, which have the equivalent diameter of $0.10,0.12$, and 0.14 m respectively. All those shapes are filled with water, alcohol, oil, and air. The power output and the efficiency are calculated for all cases. Then, these shapes are compared with normal photovoltaics (PV) that have the same section area as these shapes. After a comparison between different designs, the results of the experiments reveal that the full sphere with the same material produces a higher power output than other shapes.

\subsection{Mediums and materials}

As the light (solar radiation) enters the filled shape containers, it passes through the shape. In this situation, the shape behaves as a lens where it collects the solar radiation and concentrates the light on a focal point. Different materials (solids, liquids, gasses) are tested experimentally. The solid materials are glass, crystal, and acrylic while the liquids are oil, water, and alcohol, and the used gas is the air. Table 1 illustrates the materials specifications which are used to fill the shape containers. Those different mediums and materials are filled in the shape containers to be examined, and the power output 
and the efficiency are calculated. The experiments are repeated for different volumes in order to get more accurate results as mentioned in the earlier section.

\begin{tabular}{|c|c|c|c|c|}
\hline Materials & Kind & $\begin{array}{l}\text { Viscosity } \\
\text { (pa.s) }\end{array}$ & $\begin{array}{l}\text { Density } \\
\left(\mathrm{kg} / \mathrm{m}^{3}\right)\end{array}$ & Chemical Formula \\
\hline Air & Normal & 0.00001864 & 1.225 & $\begin{array}{c}\mathrm{N} 2, \mathrm{O} 2, \mathrm{Ar}, \mathrm{Co} 2, \mathrm{ANe}, \mathrm{He}, \mathrm{Ch} 4, \\
\mathrm{Kr}, \mathrm{H} 2, \mathrm{Xe}\end{array}$ \\
\hline Alcohol & Isopropanol & 2.1 & 0.79 & $\mathrm{C} 3 \mathrm{H} 8 \mathrm{O}$ \\
\hline Glass & Borosilicate & 600 & 2500 & $\mathrm{SiO} 2$ \\
\hline Water & Drink water & 0.00798 & 1000 & $\mathrm{H} 2 \mathrm{O}$ \\
\hline Oil & $\begin{array}{l}\text { Cooking oil } \\
\text { (Corn) }\end{array}$ & 80 & 910 & $\mathrm{C} 18 \mathrm{H} 36 \mathrm{O} 2$ \\
\hline
\end{tabular}

\subsection{Sphere's size and volume}

As the experimental results show that the full sphere with the same material produces a higher power output than other shapes, then different sphere sizes are used and listed in Table 2. The spheres with different volumes are examined then the power output and the efficiency are calculated.

\subsection{The effect of the shaped thickness}

As the experimental results show that the full sphere with the same material produces a higher power output than other shapes, then the sphere shape is selected to test the thickness of the shape. The following, acrylic thicknesses of the sphere are used: $4 \mathrm{~mm}, 5 \mathrm{~mm}, 6 \mathrm{~mm}$, and $8 \mathrm{~mm}$ thicknesses. The spheres with different thicknesses are examined then the power output and the efficiency are calculated.

Table 2. Sphere sizes and volumes.

\begin{tabular}{lcccc}
\hline Type & $\begin{array}{c}\text { Diameter: D } \\
\mathrm{cm}\end{array}$ & $\begin{array}{c}\text { Sectional Area } \\
\mathrm{cm}^{2}\end{array}$ & $\begin{array}{c}\text { Surface } \text { area } \\
\mathrm{cm}^{2}\end{array}$ & Volume $\mathrm{cm}^{3}$ \\
\hline sphere & 10 & 78.54 & 314.16 & 104.72 \\
sphere & 12 & 113.10 & 452.39 & 150.80 \\
sphere & 14 & 153.94 & 615.75 & 205.25 \\
sphere & 30 & 706.86 & 2827.43 & 942.48
\end{tabular}

\section{Results and calculations}

In order to calculate the power output of the solar cell $(w)$, the following equations are used:

$$
\mathrm{P}_{\text {out }}=\mathrm{I} \times \mathrm{V}
$$

Where I and V are the current and the voltage respectively which are measured by the multimeter. In the concentrated photovoltaic systems, the power produced is higher than that of conventional solar systems. The solar collector focuses more sunlight on the receiver, which is the solar cell in our system. To get an overview of how much the solar radiation is concentrated and to get the power input of the solar shapes, some parameters are defined to be used in the following equations:

Geometrical Concentration Ratio: is the amount of solar radiation incident on the receiver and it is obtained from the area of the collector and the receiver. Therefore, the ratio between the areas of the collector and the receiver is called geometrical concentration ratio (CR) Solankic (2013):

$$
C R=\frac{A_{\text {collector }}}{A_{\text {receiver }}}
$$


Optical Concentration Ratio: is the ratio between light intensities at the collector to the receiver. The optical concentration ratio is less than the geometrical concentration ratio since it includes the losses that are due to light intensities (solar radiation). For concentration technologies, the higher the concentration ratio is, the preferable the system is.

$$
C R_{\text {optical }}=\frac{A_{\text {collector }} \times I_{\text {collector }}}{A_{\text {receiver }} \times I_{\text {receiver }}}
$$

The solar radiation on the receiver, which is the multi-junction solar cell in our system, is:

$$
\mathrm{G}_{\mathrm{r}}=\mathrm{G} \times \mathrm{CR}\left(\mathrm{W} / \mathrm{m}^{2}\right)
$$

Where $\mathrm{G}$ is the solar radiation $(\mathrm{W} / \mathrm{m} 2)$ and Pin is the Input power of the solar cell

$$
\operatorname{Pin}=\operatorname{Gr} \times A_{\text {cell }}
$$

Electrical efficiency:

$$
\eta=\frac{P_{\text {out }}}{P_{\text {in }}}=\frac{I \times V}{G_{r} \times A_{\text {cell }}}
$$

Figure 2 shows a sample comparison between the power output of the above-mentioned shapes (which are filled with water) with the normal PV that has an equivalent diameter of $0.14 \mathrm{~m}$ (volume $=0.01508 \mathrm{~m} 3)$.

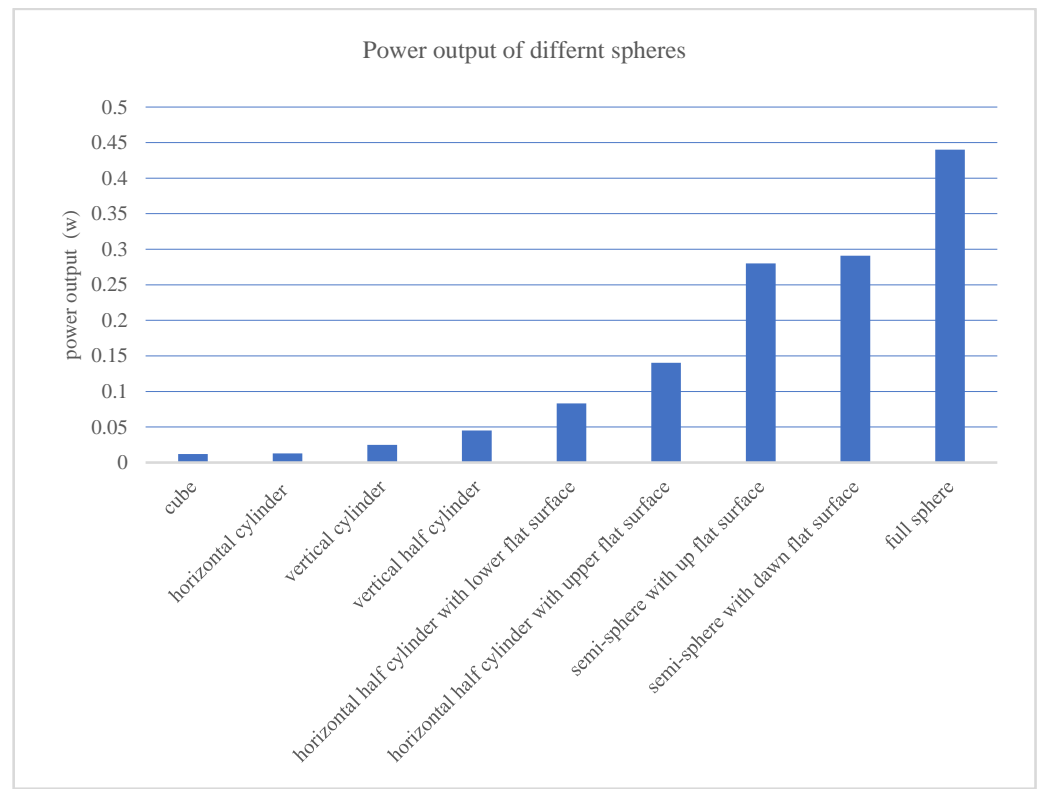

Fig. 2. A comparison between the power output of different shape designs and PVs

The experiments are repeated for different volumes and different mediums and materials. After a comparison between different designs and from the figure, it is clear that the full sphere with the same material produces a higher power output than other shapes and the normal PV. It produces around triple the power output of the semi-spheres and 4 times the power output of a PV with the same sectional area. The best shapes that produce the highest output power are arranged from the highest output power to the lower as follows: full sphere, semi-sphere with dawn flat surface, semi-sphere with an up flat surface, horizontal half cylinder with the upper flat surface, horizontal half cylinder with the lower flat surface, vertical halfcylinder, vertical cylinder, horizontal cylinder, and cube. 
As the above experimental results show that the full sphere with the same material produces a higher power output than other shapes, then different sphere sizes are used as listed in Table 2. The spheres with different volumes are examined then the power output and the efficiency are calculated. Figure 3 shows a comparison between the power output of the spheres (which are filled with water) with different sizes $(10,12,14,30 \mathrm{~cm})$. The results show that increasing the size of the sphere results in an increase in the power output. Where the $12 \mathrm{~cm}$ diameter sphere produces 0.8 times the power output of the 10 $\mathrm{cm}$ diameter sphere, and the $14 \mathrm{~cm}$ diameter sphere produces 0.9 times the power output of the $12 \mathrm{~cm}$ diameter sphere, while the $30 \mathrm{~cm}$ diameter sphere produces around 4 times the power output of the $12 \mathrm{~cm}$ diameter one.

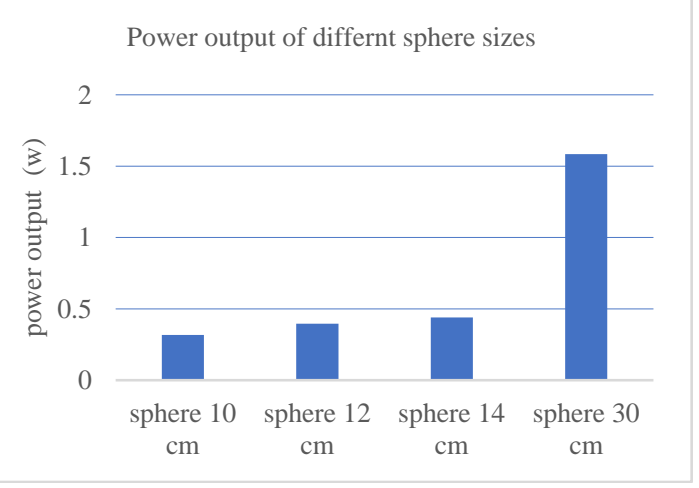

Fig. 3. A comparison between the power output of the spheres with different sizes.

Figure 4 shows a comparison between the power output of the spheres with different mediums and materials that have the same volume (solids, liquids, gasses). The solid materials are glass, crystal, and acrylic while the liquids are oil, water, and alcohol, and the used gas is the air. The experiments show that all solid materials produce the highest power output. However, these solid materials produce high heat at the same time, so they are not desirable for generating electricity. Moreover, it was noted that the sphere filled with oil produces 1.5 times more power output than the one filled with alcohol while the sphere filled with alcohol produces double the power output of the sphere filled with water. The sphere filled with air had the lowest power output compared to the other substances.

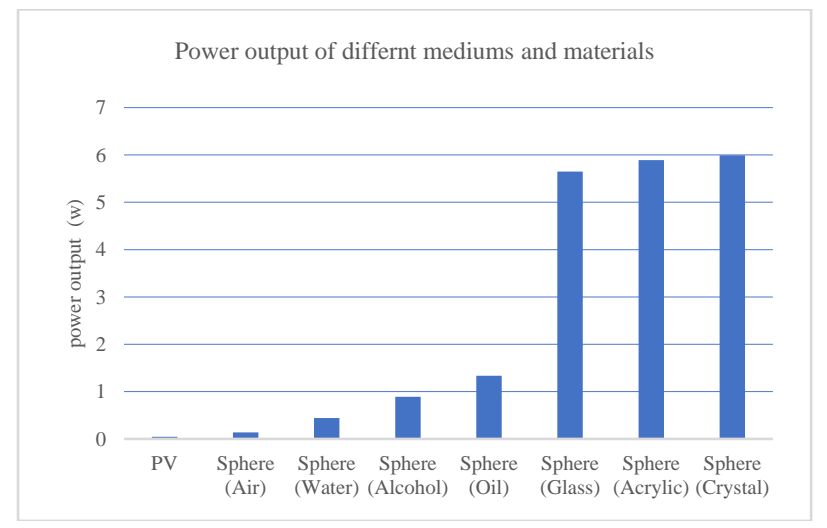

Fig. 4. A comparison between the power output of the spheres with different mediums and materials.

Figure 5 shows a comparison between the power output of the spheres of $0.14 \mathrm{~m}$ diameter filled with water with a different acrylic thickness of $4 \mathrm{~mm}, 5 \mathrm{~mm}, 6 \mathrm{~mm}$, and $8 \mathrm{~mm}$. It is verified that increasing the thickness of the ball yields in increasing the output power, it is confirmed that increasing the thickness by $1 \mathrm{~mm}$ yields in increasing the output power by 0.8 times. 


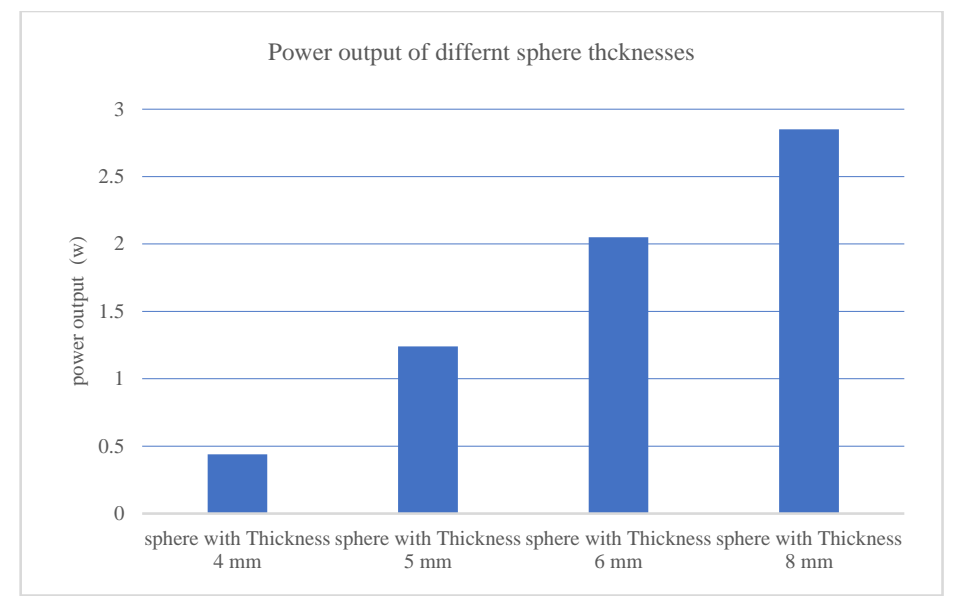

Fig. 5. A comparison between the power output of the spheres with different acrylic thicknesses.

Figure 6 illustrates a comparison between the efficiency of different shapes that have an equivalent diameter of $0.14 \mathrm{~m}$ (volume $=0.01508 \mathrm{~m} 3$ ) with different mediums and materials with the normal PV that has the same area. It is obvious that the sphere shape has higher efficiency than the normal PV. Moreover, the sphere of oil has the highest efficiency among other materials. Furthermore, the bigger the sphere size the highest efficiency.

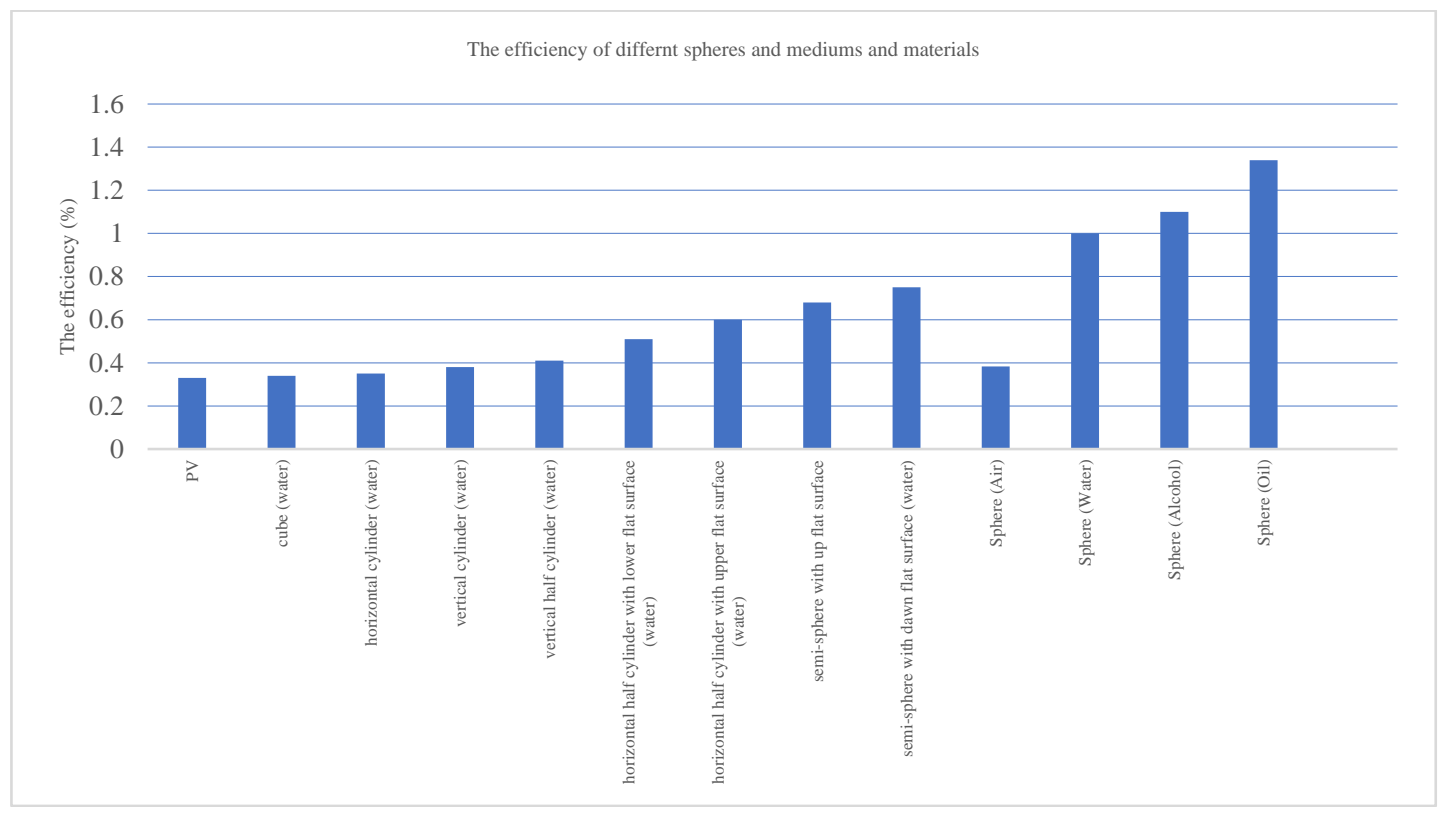

Fig. 6. A comparison between the efficiency of the different shapes and different mediums and materials.

\section{Conclusion}

Different experiments were conducted in different circumstances during the whole year in order to compare the power output and the efficiency between the different shape designs with the normal PV. It is proved that solar spheres can generate a huge amount of power that can produce much more electricity than the normal PVs. The experiments are conducted for several kinds of shapes and models that have the same volume, different volumes, and different fluid mediums. Moreover, the thickness of the shape design is also tested. The conclusions are summarized as follows: 
1. The full sphere with the same material produces a higher power output than other shapes. It produces around triple the power output of the semi-spheres and 4 times the power output of other PV with the same sectional area.

2. The results clarify that increasing the size of the shape design results in an increase in the power output and efficiency. Where the $12 \mathrm{~cm}$ diameter sphere produces 0.8 times the power output of the $10 \mathrm{~cm}$ diameter sphere, and the $14 \mathrm{~cm}$ diameter sphere produces 0.9 times the power output of the $12 \mathrm{~cm}$ diameter sphere, while the $30 \mathrm{~cm}$ diameter sphere produces around 4 times the power output of the $12 \mathrm{~cm}$ diameter one.

3. All solid materials produce the highest power output. However, these solid materials produce high heat at the same time, so they are not desirable for generating electricity.

4. The sphere filled with oil produces 1.5 times more power output than the one filled with alcohol while the sphere filled with alcohol produces double the power output of the sphere filled with water. The sphere filled with air had the lowest power output compared to the other substances.

5. Increasing the thickness of the ball yields in increasing the output power, it is confirmed that increasing the thickness by $1 \mathrm{~mm}$ yields in increasing the output power by 0.8 times.

\section{References}

[1] Hassan Abdulmouti, Khalifa Ali, Abdulla Ali, Marwan Ali, Saleh Abdullah, Rashed Abdalla. Smart Innovation Applications for a GreenHouse Using Sustainable and Renewable Energy in the UAE. DOI: 10.1109/ICASET.2018.8376782. Publisher: IEEE. Electronic. ISBN: 978-1-5386-2399-2. Print on Demand (PoD) ISBN: 978-1-5386-2400-5. IEEE Xplore Digital Library: 11 June 2018.

[2] Hassan Abdulmouti, Ali Ahmed Aljasmi, Mohamed Ali Almarzooqi, Hisham Hassan Alyasi, Mohamed Jassim Khair, Yousif Mohamed Almulla, Abdelrahman Ahmed Almulla. Generating Power from Innovative Solar Sphere. DOI: 10.1109/ICASET.2019.8714441. ISBN Information: Electronic ISBN: 978-1-5386-8271-5. Print on Demand (PoD) ISBN: 978-1-5386-8272-2. Date of Publisher: 16 May 2019. Publisher: IEEE Xplore.

[3] Hassan Abdulmouti. Measurement of Flow Structures Induced by a Bubbly Plume Using Visualization, PIV, and Image Measurement. Scholar's Press. Saarbrücken, Germany. ISBN-13: 978-3-639-51490-2. 7, June 2013.

[4] Hassan Abdulmouti. Particle Imaging Velocimetry (PIV) Technique: Principles, the typically used methods, classification, and applications. Scholar's Press. Saarbrücken, Germany. ISBN-13: 978-3-639-51249-6. 6, March 2013.

[5] M. Devaraj and S. Shanmuga Priyan. Solar Energy Collection using Spherical Sun Power Generator. International Journal of Innovative Research in Electrical, Electronics, Instrumentation, and Control Engineering IJIREEICE. Vol. 4, Special Issue 3, April 2016.

[6] Robarts, S. (2014, January 15). Rawlemon's beautiful, spherical solar energy generators. Retrieved from NEW ATLAS: https://newatlas.com/rawlemon-spherical-solar-energy-generators/30453/.

[7] Green Rhino Energy. Concentrating Photovoltaics Solar Power. Retrieved May 06, 2016.

http://greenrhinoenergy.com/solar/technologies/pv_concentration.php

[8] Fluke Corporation Fluke 83V and 87V detailed specifications. What is a digital multimeter. Retrieved May 12, 2016. http://enus.fluke.com/training/training-library/measurements/electricity/what-is-a-digitalmultimeter.html.

[9] Solanki, C. (2013). Solar Photovoltaics Fundamentals, Technologies and Applications (2nd ed., p. 237). Delhi: PHI Learning Private Limited, Rimjhim House, Patparganj Industrial Estate. 